\title{
ROLE OF VARIOUS IHC MARKERS IN CLASSIFICATION OF LUNG CARCINOMA ON ENDOBRONCHIAL BIOPSIES.
}

\section{Pathology \\ Dr. Raj Kumar Gupta

Dr. Namita
Bhutani*

\section{Dr. Sachet Dawar}

Assistant Professor,M.B.B.S, M.D., Deptt. of Pathology,S.G.T. University, Gurugram, Haryana, India.

Assistant Professor,M.B.B.S, M.D, D.N.B.,Deptt. of Pathology, S.G.T. University, Gurugram, Haryana, India. *Corresponding Author

Assistant Professor,M.B.B.S, M.D., Deptt. of Pulmonary Medicine, S.G.T. University, Gurugram, Haryana, India.

\section{ABSTRACT}

BACKGROUND: Lung cancer is the most frequently diagnosed cancer and leading cause among cancer mortality worldwide. An accurate classification is difficult in small biopsy specimens due to a variety of reasons. Therefore, there is an increasing need for additional diagnostic techniques such as immunohistochemistry.

METHODS: This study was conducted on Endobronchial biopsies of One hundred and sixty patients were subjected to routine H \& E and IHC staining.

RESULTS: The patients were in age group of 25-75 years with a mean of 55.67 years with M: F ratio of 6.61:1. NSCLC constituted the major type, contributing to $83.1 \%$ of cases. Amongst, TTF-1 and napsin-A, the later had higher sensitivity $(96.15 \%)$ as compared to TTF-1 (92.30\%) for diagnosing adenocarcinoma.

CONCLUSION: CK and p63 served as highly sensitive markers for diagnosis of squamous cell carcinoma and TTF-1 and napsin A for adenocarcinoma, forming an important diagnostic algorithm for subtyping of poorly differentiated NSCLC on small biopsies.

\section{KEYWORDS}

Adenocarcinoma; Non small cell lung carcinoma; Small cell lung carcinoma; Thyroid transcription factor-1

\section{BACKGROUND}

Lung carcinoma is the leading cause of cancer deaths in developed countries and is rising at alarming rates in the developing countries. It is the most frequently diagnosed cancer and leading cause among cancer mortality worldwide (1).

Routine sections stained with hematoxylin-eosin (H\&E) remain the most common method by which lung cancers are classified. However, typing of Non small cell lung carcinoma (NSCLC) and the more poorly differentiated cancers is often hard to achieve by $H \& E$ alone. Moreover, an accurate classification can be difficult in small biopsy specimens due to a variety of reasons, such as scant tumor cells, lack of characteristic architecture in small biopsies, artifacts in specimen prepration, and differentiation and heterogenicity of tumor. Therefore, there is an increasing need for additional diagnostic techniques such as immunohistochemistry (IHC) (2).

IHC has emerged as a powerful, adjunctive tool for the differential diagnosis of lung cancer, whether primary or secondary to lung. Primary panel of CK, LCA, synaptophysin and chromogranin differentiates SCLC, NSCLC and lymphoma, while napsin A, TTF-1 and $\mathrm{p} 63$ are used for further categorisation of NSCLC (3).

We planned to carry out this study to differentiate between primary squamous cell carcinoma and adenocarcinoma with the help of specific IHC markers and compare the cocktails of napsin A, TTF-1, and p63 in the diagnosis of NSCLC and to identify a small, accurate and cost effective IHC panel for further classification of NSCLC.

\section{MATERIALS AND METHODS}

This study was conducted in department of Pathology, S.G.T. University, Gurugram, Haryana. One hundred and sixty patients suspected of having lung cancer on basis of clinical features, radiological imaging and confirmed on histopathological examination of endobronchial biopsy, formed the study material.

Patients with lung malignancy other than primary tumor such as lymphoma, sarcoma, stromal tumor and metastasis were excluded from the study. Histopathological diagnosis was established on the routine heamatoxylin and eosin stain, IHC, and special histochemical stains like PAS and others as applicable for further classification of lung tumors.

Immunohistochemical profile of the tumor was assessed by subjecting one section each from a block of tumor to CK, p63, TTF-1, napsin-A, synaptophysin, chromogranin a, NSE, CD 56 and EGFR and results were assesed.

The whole data was subjected to statistical analysis using SPSS 20.0 software. Chi-square test was used to calculate $p$ value and appropriate statistics were applied.

The tissue biopsies submitted for histopathological study were used up in preparing wax blocks and slides. All the biomedical waste generated during the study was discarded as per the bio-medical waste (management and handling) rules 2011 guidelines.

\section{RESULTS}

In the present study, a total of 160 cases of primary lung carcinoma constituted the study group, during the period of 2018-2019, with the age of patients ranging from 25 to 75 years. Mean age at presentation was 55.67 years. Lung Carcinoma was most frequent for the age group 41-60 (89 cases $-55.6 \%$ ) and most of them were men (139 cases $86.8 \%)$. M: F Ratio in our study was $6.61: 1$.

The most common presentation was chest pain (53.1\%) followed by cough $(50 \%)$. The majority of patients presented within 3 to 6 months of onset of symptoms $(53.75 \%)$. Smokers and Non-smokers were $86.25 \%$ and $13.75 \%$ respectively in the present study. Pre-existent occupational hazards were present in $23.75 \%$ of patients. Fifteen cases $(9.4 \%)$ had a positive history of lung carcinoma in the family. Mass lesion was the most common radiological finding $(73.1 \%)$ followed by collapse $(20.62 \%)$, both in X-Ray chest and CT scan.

On the basis of histopathological features the cases were first segregated into Small cell carcinoma and Non-small cell carcinoma and confirmed by primary immunohistochemistry panel. Non-small cell carcinomas were further categorized based on their histological features. The cases which lacked the classical histological features of squamous or adenocarcinoma on $\mathrm{H} \& \mathrm{E}$ stained smears were grouped as poorly differentiated non-small cell carcinoma (PDC-NSCLC). These cases were finally classified according to their immunoprofile. All the cases of lung carcinoma, small cell as well as non-small cell carcinoma were positive for CK. A panel of IHC markers including CD 56, Synaptophysin, Chromogranin A and NSE were applied for non-small cell lung carcinoma. However, all were specific but CD 56 was the most sensitive marker for diagnosis of small cell lung carcinoma (Table I)

Table I expression Of Immunohistochemistry Markers In Small 


\begin{tabular}{|c|c|c|c|c|c|c|c|c|c|}
\hline & ADC & SQCC & \begin{tabular}{|c|} 
SCL \\
C
\end{tabular} & \begin{tabular}{|c|} 
SUB \\
TYP \\
E
\end{tabular} & \begin{tabular}{|c} 
SENS \\
ITIVI \\
TY
\end{tabular} & $\begin{array}{c}\text { SPE } \\
\text { CIFI } \\
\text { CIT } \\
\text { Y }\end{array}$ & \begin{tabular}{|l|} 
PPV \\
\end{tabular} & NPV & $\begin{array}{c}\text { p value } \\
\text { (chi- } \\
\text { square } \\
\text { ) }\end{array}$ \\
\hline CK & $26 / 26$ & $\begin{array}{c}105 / 10 \\
5\end{array}$ & $27 / 27$ & ALL & $0 \%$ & $0 \%$ & $\begin{array}{c}100 \\
\%\end{array}$ & $0 \%$ & (18.48 \\
\hline CD 56 & $0 / 26$ & $0 / 105$ & $24 / 27$ & \begin{tabular}{|c|} 
SCL \\
C
\end{tabular} & $\begin{array}{c}88.89 \\
\%\end{array}$ & $\begin{array}{c}100 \\
\%\end{array}$ & $\begin{array}{c}100 \\
\%\end{array}$ & $\begin{array}{c}97.7 \\
9 \%\end{array}$ & $\begin{array}{c}<0.001 \\
(139.0 \\
)\end{array}$ \\
\hline \begin{tabular}{|l|} 
SYNA \\
PTO
\end{tabular} & \begin{tabular}{|c|}
$0 / 26$ \\
\end{tabular} & $0 / 105$ & $22 / 27$ & \begin{tabular}{|c|} 
SCL \\
C
\end{tabular} & $\begin{array}{c}81.48 \\
\%\end{array}$ & $\begin{array}{c}100 \\
\%\end{array}$ & $\begin{array}{c}100 \\
\%\end{array}$ & \begin{tabular}{|c|}
96.3 \\
$7 \%$
\end{tabular} & $\begin{array}{l}<0.001 \\
(125.6\end{array}$ \\
\hline $\begin{array}{l}\text { CHR } \\
\text { OMO }\end{array}$ & \begin{tabular}{|l|}
$0 / 26$ \\
\end{tabular} & $0 / 105$ & $21 / 27$ & \begin{tabular}{|c|}
$\mathrm{SCL}$ \\
$\mathrm{C}$
\end{tabular} & $\begin{array}{c}77.78 \\
\%\end{array}$ & $\begin{array}{c}100 \\
\%\end{array}$ & $\begin{array}{c}100 \\
\%\end{array}$ & \begin{tabular}{|c|}
95.6 \\
$8 \%$
\end{tabular} & $\begin{array}{c}<0.001 \\
(119.07 \\
)\end{array}$ \\
\hline NSE & \begin{tabular}{|l|}
$0 / 26$ \\
\end{tabular} & $0 / 105$ & $20 / 27$ & \begin{tabular}{|c|}
$\mathrm{SCL}$ \\
$\mathrm{C}$
\end{tabular} & $\begin{array}{c}74.07 \\
\%\end{array}$ & $\begin{array}{c}100 \\
\%\end{array}$ & $\begin{array}{c}100 \\
\%\end{array}$ & $95 \%$ & $\begin{array}{c}<0.001 \\
(112.59 \\
)\end{array}$ \\
\hline
\end{tabular}

Ck: Cytokeratin Synapto: Synaptophysin Chromo: Chromogranin A Nse: Neuron Specific Enolase

Ppv: Positive Predective Value Npv: Negative Predective Value Adc: Adenocarcinoma Sqcc: Squamous Cell Carcinoma Sclc: Small Cell Lung Carcinoma

Although differentiated non small cell carcinoma did not require these stains for diagnosis, but their results served as gold standard. CK was positive in both squamous cell carcinoma and adenocarcinoma. p63 served as highly sensitive marker for diagnosis of squamous cell carcinoma and TTF-1 and Napsin A for adenocarcinoma

Based on these results, 86 cases of poorly differentiated non-small cell carcinoma (Non classifiable on histology) were again subtyped according on their immunoprofile into squamous cell carcinoma and adennocarcinoma as far as possible. On the basis of immunoprofile, 84 of the poorly differentiated cases could be categorised further but two cases were negative for all the three immunomarkers, thus, were subtyped as poorly differentiated carcinoma-NOS (Table II).

Table II Immunoprofile Of Poorly Differentiated Non Small Cell Carcinoma $(\mathrm{n}=86)$

\begin{tabular}{|c|c|c|c|c|}
\hline TTF-1 & NAPSIN-A & p63 & $\begin{array}{c}\text { NO. OF } \\
\text { CASES }\end{array}$ & FINAL DIAGNOSIS \\
\hline- & - & + & 67 & $\begin{array}{c}\text { SQUAMOUS CELL } \\
\text { CARCINOMA }\end{array}$ \\
\hline+ & + & - & 14 & ADENOCARCINOMA \\
\hline- & + & - & 02 & ADENOCARCINOMA \\
\hline- & - & - & 02 & $\begin{array}{c}\text { PDC- } \\
\text { NOS/UNDIFFERNTIATED }\end{array}$ \\
\hline+ & - & - & 01 & ADENOCARCINOMA \\
\hline
\end{tabular}

Ttf-1: Thyroid Transcription Factor- 1

Pdc-nos: Poorly Differntiated Carcinoma-not Otherwise Specified

p63 was $100 \%$ sensitive and specific for squamous cell carcinoma. Amongst, TTF-1 and napsin-A, the latter was found more sensitive for adenocarcinoma as compared to TTF-1 with sensitivity and specificity of $96.15 \%$ and $100 \%$ respectively (Table III)

Table III IHC Staining Of Different Markers In NSCLC

\begin{tabular}{|c|c|c|c|c|c|c|c|}
\hline $\begin{array}{c}\text { IHC } \\
\text { MARK } \\
\text { ER }\end{array}$ & $\begin{array}{c}\text { ADENO } \\
\text {-CARCI }\end{array}$ & $\begin{array}{c}\text { SQUA } \\
\text { NOMA } \\
\text { (26) }\end{array}$ & $\begin{array}{c}\text { SENSI } \\
\text { CELL } \\
\text { CARCI } \\
\text { NOMA } \\
\text { TIVIT } \\
\text { Y }\end{array}$ & $\begin{array}{c}\text { SPECIFI } \\
\text { CITY }\end{array}$ & PPV & NPV & $\begin{array}{c}\text { p value } \\
\text { (chi- } \\
\text { square } \\
\text { ) }\end{array}$ \\
\hline $\begin{array}{c}\mathrm{P}^{63} \\
(+/ \mathrm{T}) \\
(-/ \mathrm{T})\end{array}$ & $\begin{array}{c}0 / 26 \\
26 / 26\end{array}$ & $\begin{array}{c}105 / 105 \\
0 / 105\end{array}$ & $100 \%$ & $100 \%$ & 1 & 0.92 & $<0.001$ \\
\hline $\begin{array}{c}\mathrm{TTF}-1 \\
(+/ \mathrm{T}) \\
(-/ \mathrm{T})\end{array}$ & $\begin{array}{c}24 / 26 \\
2 / 26\end{array}$ & $\begin{array}{c}0 / 105 \\
105 / 105\end{array}$ & $92.30 \%$ & $100 \%$ & 1 & 0.98 & $<0.001$ \\
\hline $\begin{array}{c}\text { NAP-A } \\
(+/ \mathrm{T}) \\
(-/ \mathrm{T})\end{array}$ & $\begin{array}{c}25 / 26 \\
1 / 26\end{array}$ & $\begin{array}{c}0 / 105 \\
105 / 105\end{array}$ & $96.15 \%$ & $100 \%$ & 1 & 0.99 & $<0.001$ \\
\hline
\end{tabular}

NAP-A: NAPSIN-A

Napsin-A was found to be positive only in adenocarcinoma cases. But TTF-1 was also expressed in $48.14 \%$ cases of small cell carcinoma, so overall sensitivity of napsin-A is higher as compared to TTF-1. Seventy six percent of adenocarcinoma and $60 \%$ of squamous cell carcinoma were positive for EGFR.

\section{DISCUSSION}

Although there has been a long-standing quest to identify a "lungspecific tumor marker," these efforts have, until recently, largely been directed at distinguishing primary from metastatic lesions (4). Given the important therapeutic and prognostic information, identification of a "histologic specific tumor marker" has recently emerged as a valuable goal, and a number of markers have been studied. Given the inherent difficulties of trying to rely on a single antibody, panels of immunohistochemical markers have been used to improve sensitivity and specificity.

Molecular studies of lung cancers have led to the development of personalized/ targeted therapy (5). An important example is the discovery of epidermal growth factor receptor gene (EGFR) alterations, and the successful administration of EGFR tyrosine kinase inhibitors (TKIs) in lung cancer patients whose tumor harbors EGFR alterations (6). Recently, more targeted therapies aimed at specific pathways and/ or cell types have been developed and are in clinical trials. Taken together, subclassification of NSCLC plays a critical role in the clinical management of NSCLC patients (7).

In well differentiated NSCLC, morphological features are sufficient for subtyping in most of the cases. However, in poorly differentiated NSCLC subtyping is a challenging task based on H\&E alone. These cases lack the histological hallmarks of specific differentiation. It is rather acceptable to classify a case as NSCLC than to incorrectly subtype it, since in this case the patient is deprived of the targeted therapy and genetic studies.

The panel of immunomarkers used comprised $\mathrm{p}^{63}$, TTF-1 and napsinA. After the application of IHC markers, out of 86 cases of poorly differentiated non small cell carcinoma, 17 were subytped as adenocarcinoma, 67 as squamous cell carcinoma and 2 cases were NSCLC-NOS subtype, since these two cases were negative for all the three immunomarkers.

Among the IHC markers, we evaluated the role of $\mathrm{p}^{63}$ in squamous cell carcinoma. The immunoexpression of $\mathrm{p}^{63}$ was positive in all the cases of squamous cell carcinoma, while none of adenocarcinoma was positive, thus having $100 \%$ sensitivity and specificity.

When the diagnostic role of TTF-1 and napsin-A were compared, we found that sensitivity of napsin-A is more than TTF- $1(96.15 \%$ vs $92.3 \%$ ). The specificity of both in categorization of NSCLC was $100 \%$. However, TTF- 1 was also found positive in $48.14 \%$ of cases of small cell carcinoma. Similar to our study, many studies in literature have reported a higher sensitivity and specificity for napsin-A as compared to TTF-1 in subtyping of primary lung adenocarcinoma $(8,9,10)$.

EGFR testing is recommended for all locally advanced or metastatic adenocarcinoma lungs but recommendation in squamous histology is uncertain. The potential use of EGFR expression as a marker has been widely investigated, with conflicting results.

In our study, we found a total rate of $60 \%$ for the EGFR in patients with SQCLC. This rate was higher than some other studies and the possible explanation may be owing to the difference in the sex ratio of the enrolled patients. As a result, we speculate that the total rate of mutation in SQCLC might increase as the number of female cases increases. Another explanation may involve differences among races and regions, as the factors that drive genomic alteration between races are consequential (11).

Our study demonstrated that overall efficacy using p63 and napsin-A was $96.5 \%$ in poorly differentiated NSCLC. When TTF-1 was used instead of napsin-A the efficacy was $95.4 \%$. Using both TTF-1 and napsin-A $97.6 \%$ of cases could be diagnosed, which is only a marginal increase over limited panel of TTF-1/napsin-A and p63. While TTF-1 being a nuclear stain is easier to interpret, napsin-A serves as a more specific marker for differentiation of primary lung adenocarcinoma (Table IV) 
Table IV Subtyping On The Basis Of Limited Panel

\begin{tabular}{|c|c|c|c|c|c|c|c|c|}
\hline $\begin{array}{c}\text { MARKE } \\
\text { RS }\end{array}$ & $\begin{array}{c}\text { ADC } \\
\mathbf{( 2 6})\end{array}$ & $\begin{array}{c}\text { SQC } \\
\text { C } \\
\mathbf{( 1 0 5 )}\end{array}$ & $\begin{array}{c}\text { PDC } \\
\text {-NO } \\
\begin{array}{c}\text { S } \\
\text { (02) }\end{array}\end{array}$ & $\begin{array}{c}\text { SENS } \\
\text { ITIV }\end{array}$ & $\begin{array}{c}\text { SPEC } \\
\text { TFICI } \\
\text { TY }\end{array}$ & PPV & NPV & P VALUE \\
\hline TTF- & 24 & 105 & 0 & $95.4 \%$ & $100 \%$ & $\begin{array}{c}94.86 \\
\%\end{array}$ & $\begin{array}{c}9.37 \\
\%\end{array}$ & $<0.001$ \\
1+P63 & & & & & & $\%$ & \\
\hline $\begin{array}{c}\text { NAPSIN } \\
\text { A+P63 }\end{array}$ & 25 & 105 & 0 & $96.5 \%$ & $100 \%$ & $100 \%$ & $80 \%$ & $<0.001$ \\
\hline
\end{tabular}

Based on the findings that both TTF-1 and Napsin A have a high sensitivity and specificity for the diagnosis of primary lung ADCs, and p63 stain is highly sensitive and specific for squamous differentiation. Adenocarcinoma should be favoured for cases with both napsin A and TTF-1 positivity; alternatively, either TTF-1 or napsin A positivity, alongside p63 negativity, while Squamous cell carcinoma should be favoured for cases with p63 positivity alongside napsin A and TTF-1 negativity.

\section{CONCLUSION}

An accurate classification of NSCLC is essential to plan targeted therapy for the patient. However, the classification of poorly differentiated NSCLC becomes very difficult in small biopsies due to scant tissue. In such circumstances, IHC markers are of great help. At the same time, minimal panel should be used in view of small biopsies, scant material and to save the tissue for further molecular studies. p63 and napsin-A/TTF-1 should be used as first line panel, only a marginal proportion of cases require an expanded panel for subtyping.

\section{REFERENCES:}

1. Jemal A, Siegal R, Xu J, Ward E. Cancer statistics, 2010. CA Cancer J clin. 2010; 60(5):277-300.

2. Stang A, Pohlaben H, Muller KM, Jahn I, Giersiepien K. Diagnostic aggrement in the histopathological evaluation of lung cancer tissue in a population based case control study. Lung cancer. 2006; 52(1):29-36.

3. Mukhopadhyay S, Katzenstein AL. Subclassification of non small cell lung carcinoma lacking morphological differentiation on biopsy specimens: Utility of an immunohistochemical panel containing TTF-1, Napsin A, $\mathrm{p}^{63}$ and CK5/6. Am J SurgPathol. 2011;35:15-25.

4. Jagirdar J. Application of immunohistochemistry to the diagnosis of primary and metastatic carcinoma to the lung. Arch Pathol Lab Med. 2008; 132(3):384-96.

5. Zakowski MF. Lung cancer in the era of targeted therapy: a cytologist's perspective. Arch Pathol Lab Med. 2013; 137:1816-21.

6. Munfus-McCray D, Cui M, Zhang Z, Gabrielson E, Askin F, Li QK. Comparison of EGFR and KRAS mutations in primary and unpaired metastatic lung adenocarcinoma with potential chemotherapy effect. Hum Pathol. 2013;44:1286-92

7. Rivera MP, Mehta AC. Initial diagnosis of lung cancer: ACCP evidence-based clinical practice guidelines (2nd edition). Chest. 2007; 132:131S-48S.

8. Brown AF, Sirohi D, Fukoka J, Cagle PT, Nicolas MP, Tacha D. Tissue preserving antibody cocktails to differentiate primary squamous cell carcinoma, adenocarcinoma and small cell carcinoma of lung. Arch Pathol Lab Med. 2013; 137(9):1274-81.

9. Tacha D, Yu C, Bremer R, Qi,W, Ha T. A 6-Antibody Panel for the Classification of Lung Adenocarcinoma Versus Squamous Cell Carcinoma. Appl Immunohistochem Mol Morphol 2012;20:201-7.

10. Stoll LM, Johnson MW, Gabrielson E, Askin F, Clark DP, Li QK. The utility of napsin-A in the identification of primary and metastatic lung adenocarcinoma among cytologically poorly differentiated carcinomas. Cancer Cytopathol. 2010; 118:441-9.

11. Ellison G, Zhu G, Moulis A, et al. EGFR mutation testing in lung cancer: a review of available methods and their use for analysis of tumor tissue and cytology samples. J Clin Pathol 2013; 66:79-89. 